\title{
Viscosity improvement of recycled poly (ethylene terephthalate) from waste bottles by adding antioxidants and chain-extender
}

\author{
Isarankura Na Ayutthaya Siriorn ${ }^{1,2,3}{ }^{*}$, Bunyarak Munchumart ${ }^{1}$, Boondeacha Natanicha ${ }^{1}$, Sangrawee Nut $^{1}$, \\ Markmee Nopparat ${ }^{1}$, and Haaian Suchart ${ }^{1}$. \\ ${ }^{1}$ Department of Power Engineering Technology, College of Industrial Technology, King Mongkut's University of Technology North \\ Bangkok, Bangkok, Thailand.10800 \\ ${ }^{2}$ Research Centre for Combustion Technology and Alternative Energy - CTAE, College of Industrial Technology, King Mongkut's \\ University of Technology North Bangkok, Bangkok, Thailand. 10800 \\ ${ }^{3}$ Center for Design and Engineering for Railway and Modern Transport System, King Mongkut's University of Technology North \\ Bangkok, Bangkok, Thailand. 10800
}

\begin{abstract}
This research work is focused on the viscosity improvement of recycled poly(ethylene terephthalate) (rPET) from waste bottles by adding antioxidants and multi-functional reactive polymer (Joncry ADR 4468, chain extender). The achieve the objective of this work the investigated was broken into two parts. The first part studied the effect of rPET viscosity after adding various types of antioxidants and stabilizer such as $\operatorname{Irgafos}{ }^{\circledR} 168$, Tinuvin ${ }^{\circledR} 770$, Irganox ${ }^{\circledR} 1010$. The second part observed the effect of viscosity after it was blended with chain extender at $0,0.2,0.4,0.6$ and $0.8 \mathrm{pph}$. rPET was then dried in the oven at $120{ }^{\circ} \mathrm{C}$ for $12 \mathrm{hrs}$, to deplete the moisture. Then, the dried rPET (mixed with the chemicals above) was extruded into a compound using a twin screw extruder. The shear viscosity of the extruded compound was then measured using a rotational rheometer at $270{ }^{\circ} \mathrm{C}$. The results revealed that the addition of chain extender increased the shear viscosity and the tensile strength at break of rPET. Therefore, the chain extender interacted with chains, which could change the structure to be the longer chains, branching or network structures. These structures are entangled and interrupt the movement of the molecular chains. It can be concluded that the viscosity of rPET can be improved by adding a chain extender at $0.6 \mathrm{pph}$, and the antioxidants of $\operatorname{Irgafos}{ }^{\circledR} 168$, Tinuvin ${ }^{\circledR} 770$ and $\operatorname{Irganox}{ }^{\circledR} 1010$ at $0.2,0.1$ and 0.5 pph, respectively.
\end{abstract}

Keyword. rPET, Antioxidant, Chain-extender, Viscosity.

\section{Introduction}

Nowadays, the world produces around 300 million tons of plastic waste. One popular type of recycle plastic is PET waste bottles [1, 2]. PET or poly (ethylene terephthalate) is a kind of thermoplastic polymer that has a high molecular weight, which is used to produce drink and beverage bottles. The so-called "PET bottles" [3]. PET bottles are light weight bottles, which have high durability, toughness, good impact and pressure resistance, high gas permeability resistance, heat resistance and flame retardant $[4,5,6]$. PET is not a type of plastic that is easy to decompose. Therefore, recycling PET is a solution to make PET more environmentally friendly [7]. Presently, the recycled PET can be used to produce various type of products. Such as fibers, fabric, packaging, clothing, carpet, suitcase, and core materials [6].

For the recycle process, many types of PET bottles (such as clear bottles, colored bottles, thick bottles, and thin bottles etc.) is to wash and ground them into small pieces or flake. Then, remelt the PET flakes in an extrusion machine into rPET extrudate, then cut into pellets. However, the process of washing and grinding PET bottles into rPET flakes involves water and moisture and these are the main problem of the recycle process. Moisture and water will cause hydrolysis degradation during the extrusion process. Therefore, the molecular chain of rPET becomes shorter, decreasing the viscosity and melting strength of the polymer. This affects the formability of melted rPET, which could not be formed into a strong product $[2,4,8,9,10,11,12]$. To fix this problem, the rPET properties can be improved to better support the extrusion process. For example, by increasing the melted strength by increasing the molecular weight and the modifying the molecular structure into a branching structure by adding chain extenders $[2,4,6,12,13]$.

Another way to increase the melt strength of rPET is by adding the antioxidants and stabilizers. Because, during the degradation process. The free-radicals, polymer radicals and peroxy radicals always occur. These radicals interact with the surrounding oxygen and hydrogen (from air and moisture) rapidly, which induced polymer chain cleavage quickly resulting in decreasing the melt strength, which can serve process-ability

* Corresponding author: siriorn.i@cit.kmutnb.ac.th 
limitation $[14,15,16]$. From this reason, the antioxidants and stabilizers were added in some research. However, rarely research investigated on the effect of antioxidant and stabilizer on the viscosity and tensile properties of rPET. So, the proper amount of these additives has not yet been investigated.

In this work focused on the improvement of process-ability of rPET by improve heat resistance and increased molecular chain of rPET during extrusion process are of interest. The aims of this work were to investigate the types and optimum concentration of antioxidant and stabilizers used during polymer processing. Afterwards, the concentration of chain extender was investigated. Lately, the mechanical properties such as tensile strength at break, elongation at break and Young's modulus were also interest.

\section{Materials and methods}

\subsection{Materials}

PET flakes from PET waste bottles were purchased from Thai Plastic Recycle Group Company Limited. Flakes and chemical structure and of PET as shown in Fig.1.
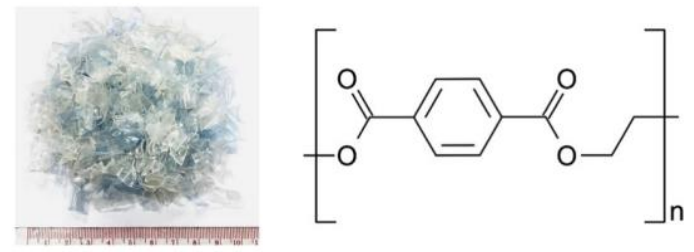

Fig.1 Flakes and chemical structure of PET.

\subsection{Chemicals}

Phenolic antioxidant (heat stabilizer): Pentaerythritol tetrakis(3-(3,5-di-tert-butyl-4-hydroxyphenyl) propionate (Irganox $\left.{ }^{\circledR} 1010\right)$, molecular weight $1178 \mathrm{~g} / \mathrm{mol}$. Hindered amine light stabilizer: Bis(2,2,6,6-tetramethyl-4piperidyl) sebaceate (Tinuvin ${ }^{\circledR} 770$ ), molecular weight $481 \mathrm{~g} / \mathrm{mol}$; and antioxidant (peroxide decomposer type) Tris (2,4-di-tert-butylphenyl) phosphite (Irgafos ${ }^{\circledR} 168$ ), molecular weight $646.9 \mathrm{~g} / \mathrm{mol}$. The chemicals above were supplied from Merit Solution Company Limited. Chemical structure of Tinuvin ${ }^{\circledR} 770$, Irganox ${ }^{\circledR} 1010$, and Irgafos $^{\circledR} 168$ as shown in Fig.2-4.

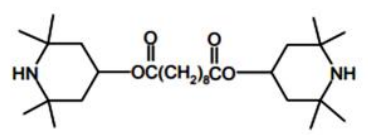

Fig.2 Chemical structure of Tinuvin ${ }^{\circledR} 770$.

Chain extender (multi-functional reactive polymer): Acrylic epoxy resin (Joncryl ${ }^{\circledR}$ ADR4468) was received from Chemical Innovation Company Limited. The chemical structure of Joncryl ${ }^{\circledR}$ ADR4468 was shown in Fig.5.

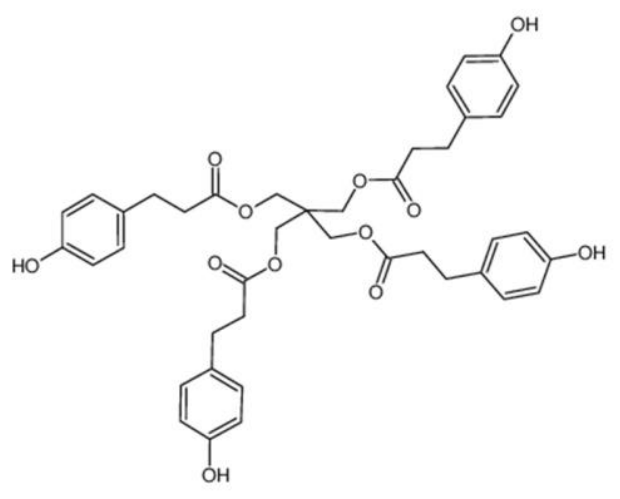

Fig.3 Chemical structure of Irganox ${ }^{\circledR} 1010$.<smiles>CC(C)(C)c1ccc(O[PH]2(OC(C)(C)c3ccc(C(C)(C)C)cc3C(C)(C)C)Oc3ccc(C(C)(C)C)cc3C(C)(C)O2)c(C(C)(C)C)c1</smiles>

Fig.4 Chemical structure of Irgafos ${ }^{\circledR} 168$.<smiles>[R]OC(=O)C(C)(CC(C)(C)C)CC(C)(C)C(C(=O)OCC1CO1)C(=O)OCC1CO1</smiles>

Fig.5 Chemical structure of Joncryl ${ }^{\circledR}$ ADR4468.

\subsection{Equipment}

A co-rotating twin screw extrusion machine (XINDA, SHJ-200) was used to prepare the rPET compounds. An oven with ventilation (Memmert, UN750plus) was used to dry the flakes and pellets of plastic. A hot-press compression molding machine (ENMACH, XH406CEWP) was used to prepare the specimens. A rotational rheometer (Kinexus, $\mathrm{Lab}+$ ) was used to measure the viscosity of rPET flakes and rPET compounds. A universal testing (Testometric, M500$25 \mathrm{AT}$ was used to measure the mechanical strength of specimens.

\subsection{Preparation of rPET flakes}

rPET flakes, which were cut and ground from PET waste bottles were dried in an oven (Memmert UN750plus) at $120{ }^{\circ} \mathrm{C}$ for $12 \mathrm{~h}$. PET flakes should be dried to prevent hydrolysis degradation of PET during the recycle processing (extrusion process). 


\subsection{Preparation of rPET Compounds}

Dried rPET flakes, were mixed with antioxidants and a chain extender as shown in Table 1 and 2. Next, these formulas were compounded through the mixing of rPET flakes with various additives with the formula in accordance with Table 2 . The compounds were mixed in a co-rotating twin screw extruder (XINDA, SHJ-200) with a twin rod die $(2 \mathrm{~mm}$. diameter each). The temperature profiles from the feed zone to the die zone were $180-180-200-220-220-200{ }^{\circ} \mathrm{C}$, respectively. The screw rotating speed was $60 \mathrm{rpm}$. The extrudate rod was cooled under water and collected by a pulling unit. Then the compounds were cut into pellet form (Fig. 6).

Table 1. Antioxidants content in rPET compounds.

\begin{tabular}{|c|c|c|c|}
\hline Formulas & $\begin{array}{c}\text { Tinuvin }^{\circledR} 770 \\
\text { (pph) }\end{array}$ & $\begin{array}{c}\text { Irgafos }^{\circledR} \text { 168 } \\
\text { (pph) }\end{array}$ & $\begin{array}{c}\text { Irganox }^{\circledR} 1010 \\
\text { (pph) }\end{array}$ \\
\hline rPET flake & - & - & - \\
\hline Anti-1 & - & - & 0.5 \\
\hline Anti-2 & 0.1 & 0.2 & 0.5 \\
\hline $\begin{array}{c}\text { Anti-3 } \\
\text { (or Jon-0) }\end{array}$ & 0.1 & 0.2 & 0.5 \\
\hline
\end{tabular}

Table 2. Chain extender content in rPET compounds.

\begin{tabular}{|c|c|c|}
\hline $\begin{array}{c}\text { Compound } \\
\text { formulas }\end{array}$ & $\begin{array}{c}\text { rPET } \\
\text { (pph) }\end{array}$ & Joncryl ${ }^{\circledR A D R ~ 4468}$ \\
\hline Pure-PET & 100 & - \\
\hline Jon-0.0* & 100 & 0 \\
\hline Jon-0.2* & 100 & 0.2 \\
\hline Jon-0.4* & 100 & 0.4 \\
\hline Jon-0.6 * & 100 & 0.6 \\
\hline Jon- $0.8 *$ & 100 & 0.8 \\
\hline
\end{tabular}

Remark: * this formula has Irganox ${ }^{\circledR} 1010\left(0.5\right.$ pph), Tinuvin ${ }^{\circledR 770}(0.1$ pph) and Irgafos ${ }^{\circledR 168}(0.2 \mathrm{pph})$.

\subsection{Specimen preparation from rPET compounds}

The pellet of rPET compound was dried in an oven at $120{ }^{\circ} \mathrm{C}$ for $12 \mathrm{~h}$. Then the compound was fabricated into a specimen of $(120 \mathrm{~mm} \times 120 \mathrm{~mm} \times 2 \mathrm{~mm})$ with a hotpress hydraulic machine (ENMACH XH-406CEWP).

The details of the fabrication process (temperature and pressure) of the specimen are described below. The rPET compound was added into the mould. Then, the mould was put into the hot-press hydraulic machine using a temperature of $280^{\circ} \mathrm{C}$, and it was pressed at 0.5 MPa for 5 mins. Then, adjusted the pressure to $10 \mathrm{MPa}$ for 2 mins. After that, released the pressure to $0 \mathrm{MPa}$ for
10 second (the air or bubble inside the polymer melt was released at this stage). Next, increased pressure again to $10 \mathrm{MPa}$ for 10 mins. Afterwards, transfer the mould to the cooling section at $10 \mathrm{MPa}$ for $1 \mathrm{~min}$. The specimens were removed from the mould and cut into dumbbell shapes by following the standard ASTM D638 type IV. The samples were tested by a universal testing machine to obtain the result of tensile strength at breakage, elongation at breakage and Young's modulus.

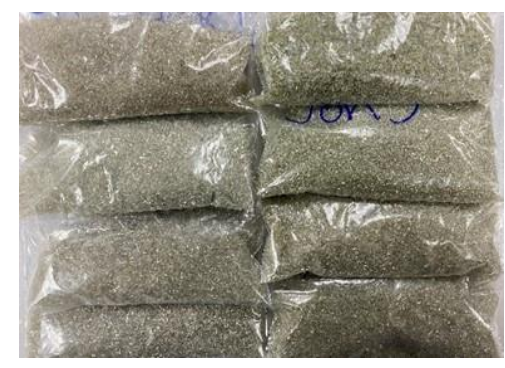

Fig.6 Pellets of rPET compounds

\subsection{Testing and measurement methods}

Viscosity measurement: rPET compound pellets (from Table 2) were dried at $120^{\circ} \mathrm{C}$ for $12 \mathrm{~h}$. Then, they were measured for viscosity by a rotational rheometer (Kinexus, $\mathrm{Lab}^{+}$) using cone $40 \mathrm{~mm}$. diameter, at $270{ }^{\circ} \mathrm{C}$. Mechanical testing: the samples with dumbbell shapes (ASTM D638 type IV) were tested by using a universal testing machine. Load cell and speed were $10 \mathrm{kPa}$ and 5 $\mathrm{mm} / \mathrm{min}$, respectively.

\section{Results and Discussions}

\subsection{Appearance of the rPET compounds}

Fig.7 show the rPET extrudate from 1.2.2, which are Anti-0, Anti-1, Anti-2, Anti-3 (or Jon-0), Jon-1, Jon-2, Jon-3 and Jon-4.

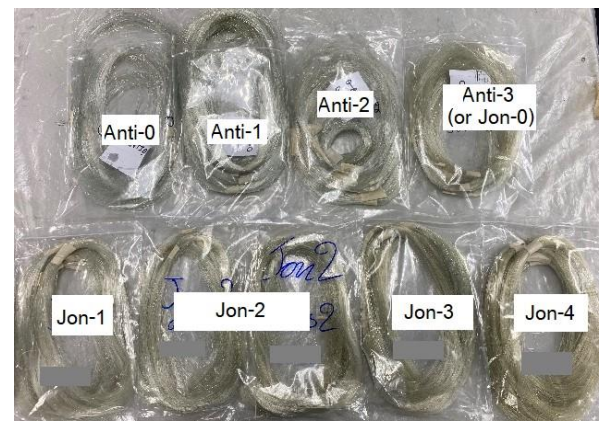

Fig.7 Extrudate of rPET compounds

It was found that the diameter of Jon-4 was bigger than other formulas. It was because, Jon- 4 has the highest content of chain extender (Joncry ${ }^{\circledR}$ ADR4468), which could have more branches than others. 


\subsection{Viscosity of the rPET compounds}

\subsubsection{Viscosity of rPET compounds with various types of antioxidants}

Fig. 8 shows the comparative of shear viscosity of rPET compounds, including rPET flake, Anti-1, Anti-2, Anti-3 (or Jon-0), which were different in types and the content of antioxidant, including $\operatorname{Irgafos}{ }^{\circledR} 168$, Tinuvin ${ }^{\circledR} 770$ and Irganox ${ }^{\circledR} 1010$.

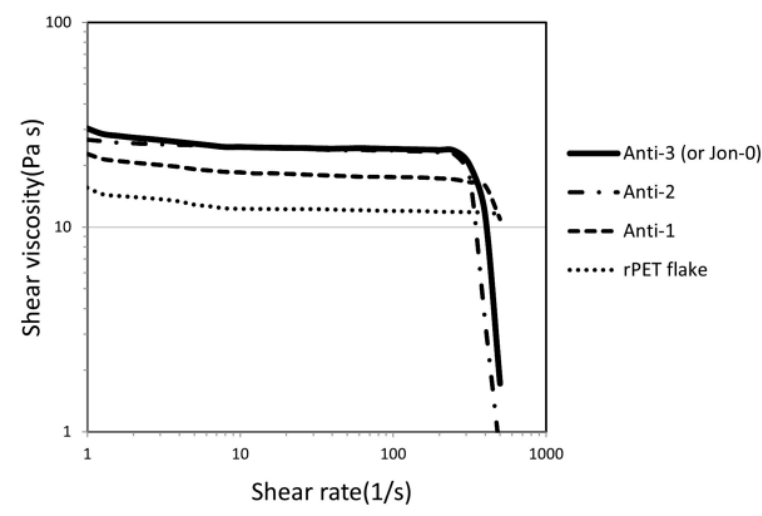

Fig.8 Viscosity value of rPET compounds (rPET flake, Anti-1, Anti-2, Anti-3 (or Jon-0).

Fig.7 shows viscosity value of rPET flake and various rPET compounds (Anti-1, Anti-2, Anti-3 (or Jon-0)). The non-Newtonian behaviour can be observed from all materials. The lowest viscosity was found in rPET flake. This flake came from the ground PET waste bottle directly without adding more additives. For Anti1 , the viscosity value increased when added $0.5 \mathrm{pph}$ of Irganox ${ }^{\circledR} 1010$ (heat stabilizer).

Notably, when adding other types of additives, Anti-2 (which added Tinuvin ${ }^{\circledR} 770$ and $\operatorname{Irgafos}{ }^{\circledR} 168$, at 0.1 and $0.2 \mathrm{pph}$, respectively) and Anti-3 (or Jon-0), which added Tinuvin ${ }^{\circledR} 770, \quad \operatorname{Irgafos}^{\circledR} 168$ and Irganox ${ }^{\circledR} 1010$ equal to $0.1,0.2$ and $0.5 \mathrm{pph}$, respectively. It was found that they were of similar viscosity value. Therefore, the main additives that help to improve the viscosity value are Tinuvin ${ }^{\circledR} 770$ and $\operatorname{Irgafos}{ }^{\circledR} 168$, at 0.1 and 0.2 , respectively. It was because, Tinuvin ${ }^{\circledR} 770$ and Irgafos ${ }^{\circledR} 168$ are primary antioxidants (or radical scavenger) and peroxide decomposer, respectively. They can reduce the free radicals inside polymer effectively [14]. Meanwhile, Irganox ${ }^{\circledR} 1010$ was not significantly effective. It was because the molecular weight of Irganox ${ }^{\circledR} 1010$ is higher than $\operatorname{Tinuvin}^{\circledR} 770$ and Irgafos ${ }^{\circledR} 168$. Furthermore, the structure of Irganox ${ }^{\circledR} 1010$ is more complex and hinder than the others, which did not move rapidly (actively) to catch the radical in the polymer melt during the extrusion process. rPET is a kind of polyester that can degrade easily via hydrolysis reaction, which means it will break the chain into shorter chains and small radicals quickly. Hence, the addition of proper antioxidants will reduce the degradation rate of the polymer significantly.

\subsubsection{Viscosity of rPET compounds with various content of chain extender}

Fig.9 shows the comparative of shear viscosity of rPET compounds, including Jon-0, Jon-1, Jon-2, Jon-3 and Jon-4, which were different in the content of chain extender (Joncryl ${ }^{\circledR}$ ADR4468). All formulas were added Tinuvin $^{\circledR} 770$, Irgafor ${ }^{\circledR} 168$ and $\operatorname{Irganox}^{\circledR} 1010$ at $0.1,0.2$ and $0.5 \mathrm{pph}$, respectively.

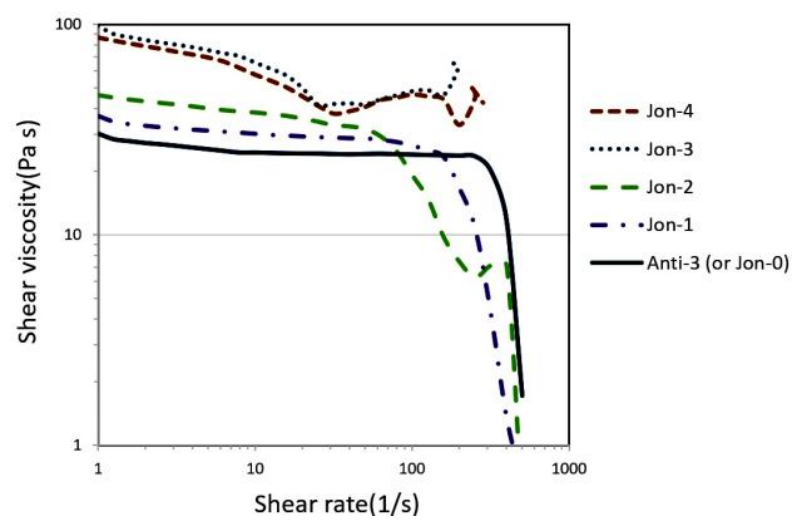

Fig.9 Viscosity value of rPET compounds (Jon-0, Jon-1, Jon-2, Jon-3 and Jon-4).

Fig.9 shows the high viscosity value of Jon-3 and Jon-4. As such these formulas have high concentration of chain extender when compared with other formulas. The chain extender interacted with the molecular chain, including short and long molecular chains. The interaction between rPET chains and the chain extender occurred at the hydroxy terminal end groups of PET and an epoxy-based chain extender, via esterification and etherification, respectively [13]. Consequently, rPET has a higher molecular weight and more branching, which increases the viscosity value.

\subsection{Mechanical Properties}

Fig.10, 11 and 12 shown the tensile strength at breakage, elongation at breakage and Young's modulus of various rPET compounds, which are Jon-0, Jon-1, Jon-2, Jon-3 and Jon-4. Fig.10, Jon-0, Jon-1 and Jon-2 show the same value of tensile strength at breakage. Therefore, the quantity of chain extender, 0.2 and $0.4 \mathrm{pph}$, were not significant enough to improve the chain branching and chain entanglement of polymer chains. As a result, it cannot improve the value of tensile strength at break of these specimens. On the other hand, it was found that the high value of the tensile strength at breakage were Jon-3 and Jon-4, which were $30.26 \pm 1.15$ and $30.64 \pm 14.24$ $\mathrm{MPa}$, respectively. This is because these formulas have a high concentration of chain extender, which makes rPET higher in molecular weight and allows more branching. $[4,8,9,17]$. Furthermore, the rPET chains have a higher content of chain entanglement resulting in the higher value of tensile strength at break. The higher in chain 
entanglement is related to the higher viscosity value of Jon-3 and Jon-4. As shown in Fig.9.

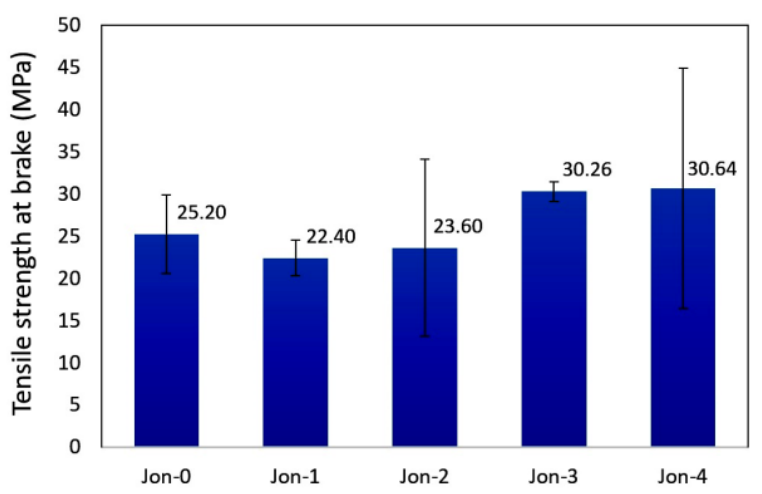

Fig.10 Tensile strength at break of various rPET compounds (Jon-0, Jon-1, Jon-2, Jon-3 and Jon-4).

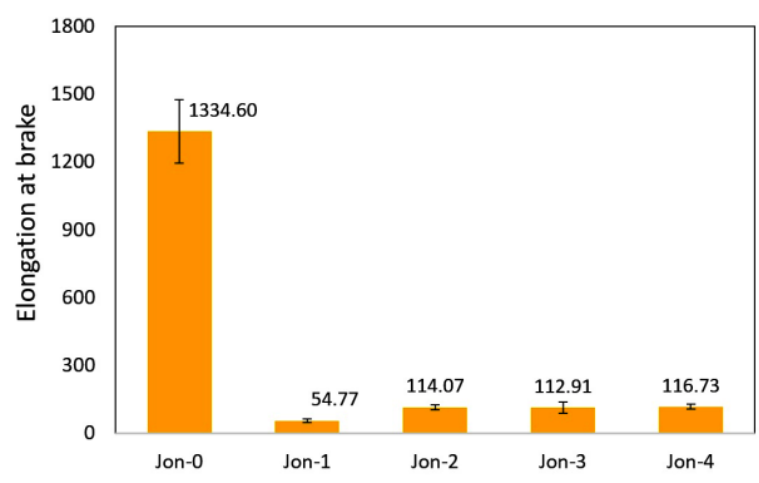

Fig.11 Elongation at break of various rPET compounds (Jon-0, Jon-1, Jon-2, Jon-3 and Jon-4).

From Fig.11 shows the elongation at breakage of rPET compounds with and without a chain extender. It was found the decrease of elongation at breakage values decreases rapidly after adding a chain extender, compared with rPET compound without a chain extender. Therefore, the chain extender interacted with chains, which could change the structure to be the longer chains, branching or network structures [4]. These structures are entangled and interrupt the movement of the molecular chain. However, with the higher concentration of a chain extender it was found a slightly increased of the elongation value, due to the branching effect of the compounds.

Fig.12 shows the Young's modulus of rPET compounds with and without a chain extender. It was found there was an increasing trend of the Young's modulus values of Jon-1, Jon-2 and Jon-3. In contrast, Jon- 4 shows the rapid decrease of the modulus value after adding a chain extender of more than $0.6 \mathrm{pph}$. This was because the concentration of the chain extender is too high. It will change the chain structure of the compound to be a branching structure with the network structure [4]. If the compound has the network structure (gel content), the area of network will lock the chain, which means the chain cannot move or slide past each other.

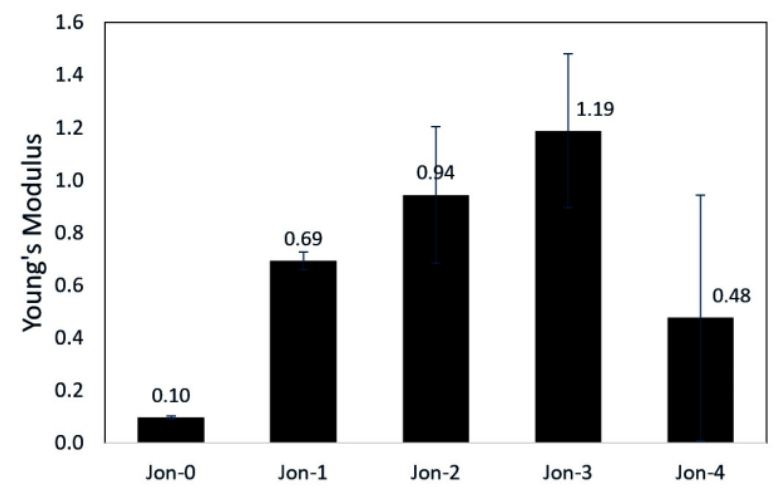

Fig.12 Young's modulus of various rPET compounds (Jon-0, Jon-1, Jon-2, Jon-3 and Jon-4).

\section{Conclusion}

The shear viscosity of rPET can be improved by adding the additives of two systems. The first system represents the rPET that adding of Tinuvin ${ }^{\circledR} 770$ and $\operatorname{Irgafos}{ }^{\circledR} 168$ at 0.1 and $0.2 \mathrm{pph}$, respectively. The second system represents the rPET that adding of Tinuvin ${ }^{\circledR} 770$, Irgafos ${ }^{\circledR} 168$ and $\operatorname{Irganox}{ }^{\circledR} 1010$ at $0.1,0.2$ and $0.5 \mathrm{pph}$, respectively. Moreover, the viscosity and mechanical properties (tensile strength at breakage, elongation at breakage and the Young's modulus) of rPET, can be improved by adding the chain extender (Joncryl ${ }^{\circledR}$ ADR 4468) at $0.6 \mathrm{pph}$.

\section{Acknowledgement}

This research was funded by Thailand Science Research and Innovation Fund, and King Mongkut's University of Technology North Bangkok with Contract no. KMUTNBMHESI-64-14.5). The authors would like to thank Research Center of Innovative Rubber (RIR), King Mongkut's University of Technology North Bangkok for supporting the fabrication processing and the characterization equipment. We would also like to thank Merit Solution Company Limited and Chemical Innovation Company Limited to support the antioxidants and chain extender, respectively.

\section{References}

1. T.M. Letcher, Plastic waste and recycling : Environmental Impact, Societal, Issues, Prevention, and Solutions (Academic Press, London, 2020)

2. V.A. Szabó, G. Dogossy, Investigation of flame retardant rPET foam, Periodic Polytechnica Mechanical Engineering, 2019

3. P. Kongsupapkul, K. Cheenkachorn, S. Tontisirin, Effects of MgO-ZSM-23 zeolite catalyst on the pyrolysis of PET bottle waste, KMUTNB international journal of applied science, 10, 3 (2017) : 205-211.

4. S. Makkam, W. Piewjan, W. Harnnarongchai, The effect of chain extender on rheological properties of 
recycled poly (ethylene terephthalate), RMUTP Research Journal Humanities and Social Sciences, 8, 2 (2014) : 70-80.

5. C. Fan, C. Wan, F. Gao, C. Huang, Z. Xi, Z. Xu, L. Zhao, T. Liu, Extrusion foaming of poly(ethylene terephthalate) with carbon dioxide based on rheology analysis, Journal of Cellular Plastics, 0, 0 (2015) : 1-22

6. S. Yao, T. Guo, T. Liu, Z. Xi, Z. Xu, L. Zhao, Good extrusion foaming performance of long-chain branched PET induced by its enhanced crystallization property, Journal of Applied Polymer Science, (2020)

7. F. Ronkay, B. Molnár, F. Szalay, D. Nagy, B. Bodzay, I. E. Sajó, K. Bocz, Development of flameretarded nanocomposites from recycled PET bottles for the electronics industry, Polymer, 11, 233 (2019)

8. L. Incarnato, L. Scarfalo, L. Maio, D. Acierno, Structure and rheology of recycled PET modified by reactive extrusion, Polymer, 41, 18 (2000): 68256831

9. R. Assadi, X. Colin, J. Verdu, Irreversible structure changes during PET recycling by extrusion, Polymers, 45, 13 (2004) : 4403-4412

10. L.K. Nait-Ali, X. Colin, A. Bergeret, Kinetic analysis and modelling of PET macromolecular changes during its mechanical recycling by extrusion, Polymer Degradation and Stability, 96, 2 (2011) : 236-246

11. F. Awaja, D. Pavel, Recycling of PET, European Polymer Journal, 41, 7 (2005) : 1453-1477
12. V.A. SzabÓ, G. Dogossy, Structure and properties of closed-cell foam prepared from rPET, IOP Conf. Series: Materials Science and Engineering, 426 (2018) :012043

13. M. Aksit, S. Gröschel, U. Kuhn, A. Aksit, K. Kreger, H-W. Schmidt, V. Altstädt, Low-density polybutylene terephthalate foams with enhanced compressive strength via a reactive-extrusion process, Polymers, 12, 2021 (2020)

14. S. Isarankura Na Ayutthaya, J. Wootthikanokkhan, Investigation of the photodegradation behaviors of an ethylene/vinyl acetate copolymer solar cell encapsulant and effects of antioxidants on the photostability of the material, Journal of Applied Polymer Science, 107 (2008) : 3853-3863

15. A. Gooneie, P. Simonetti, K. Salmeia, S. Gaan, R. Hufenus, M. Heuberger, Enhanced PET processing with organophosphorus additive : Flame retardant products with added-value for recycling, Polymer Degradation and Stability, 160 (2019) : 218-228

16. C. Huang, X. Dang, R. Bei, Y. Zhao, C. Li, Q. Chen, S. Wang, Effect of SiOx layer on preventing the migration of plasticizer and antioxidant from polyethylene terephthalate films, Iranian Polymer Journal, 28 (2019) : 173-182

17. M. Villalobos, A. Awojulu, G. Greeley, G. Turco, G. Deeter, Oligomer chain extenders for economic reprocessing and recycling of condensation plastics, Energy, 31, 15 (2006) : 3272-3234 